\section{La Comisión Europea adopta la primera estrategia común para la cultura}

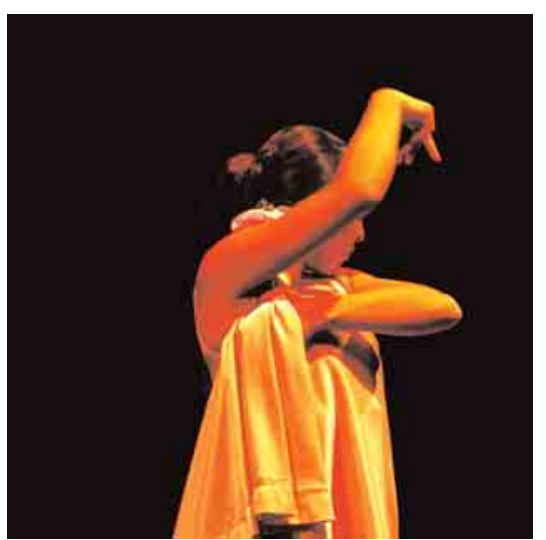

(1) Esencia. IX Festival de Música y Teatro Sacro-Ritual de Riogordo. Málaga / Dolores Lobillo ARANDA

La Comisión Europea adoptó, el pasado 10 de mayo, una comunicación sobre el papel de la cultura en el mundo globalizado, en la que se propone la creación de la primera estrategia europea para la cultura. Denominada "Una agenda europea para la cultura en un mundo globalizado", la comunicación destaca el papel primordial que ocupa la cultura en el proceso de integración europeo, y propone la creación de una agenda cultural para Europa, y se acompaña de un informe que describe los medios por los que la UE apoya a la cultura. Ambos documentos han sido elaborados tras los resultados obtenidos después de una consulta pública realizada a todos los agentes sociales relacionados con el mundo de la cultura.

La estrategia europea se basa en tres pilares fundamentales: la promoción de la diversidad cultural y el diálogo intercultural; la promoción de la cultura como catalizador para la creatividad, establecida en la Estrategia de Lisboa; y la promoción de la cultura como elemento vital para las relaciones internacionales de la Unión Europea.

En la Comunicación (ec.europa.eu/culture/ eac/communication/comm_en.html) se proponen medidas para que la cultura tenga un puesto aún más importante en el diálogo político con los países y las regiones del mundo, promoviendo los intercambios culturales e integrando sistemáticamente la cultura en los programas y proyectos de desarrollo.

Pilar Tassara Andrade. EPGPC

\section{Presentación oficial del Centro de Estudios "Paisaje y Territorio"}

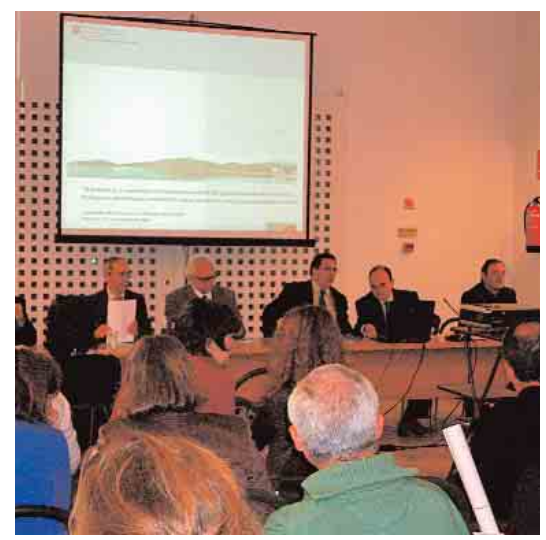

(1) Sesión del encuentro Actualidad del Paisaje / SILVIA FERNÁndez CACHO

El pasado 18 de marzo se celebró el encuentro Actualidad del Paisaje en el Antiguo Convento de Santa María de los Reyes a iniciativa de la Consejería de Obras Públicas y Transportes en el que se presentó de forma oficial el Centro de Estudios "Paisaje y Territorio". El CEPT se crea en 1985 a través de un convenio marco de colaboración entre dicha Consejería y las Universidades andaluzas, con la finalidad de fomentar la interacción positiva entre las respectivas líneas de actividad, investigadores, científicos y docentes y del ejercicio de competencias en materia de paisaje y ordenación del territorio.

La presentación del CEPT corrió a cargo de su director, Florencio Zoido Naranjo, que explicó sus líneas de actuación prioritarias. Joan Ganyet Solé, D. G. de Arquitectura y Paisaje de Cataluña, expuso las políticas de paisaje en Cataluña. Las políticas andaluzas se presentaron en una mesa redonda, moderada por Damián Álvarez Sala, Presidente del Consejo Rector del CEPT, en la que partiparon José Román Montes, D. G. de Desarrollo Rural, Román Fernández-Baca Casares, Director del IAPH, Antonio Llaguno Rojas, Secretario General de Políticas Ambientales, Ignacio Pozuelo Meño, D. G. de Planificación de la Consejería de Obras Públicas y Transportes y Antonio Zoido Naranjo de la Consejería de Turismo. El Encuentro se completó con una visita a la Exposición Los Paisajes Andaluces en compañía de su comisario, el artista sevillano Juan Fernández Lacomba.

Silvia Fernández Cacho

\section{El Centro de \\ Emigración Alemana \\ de Bremerhaven, mejor museo europeo 2007}

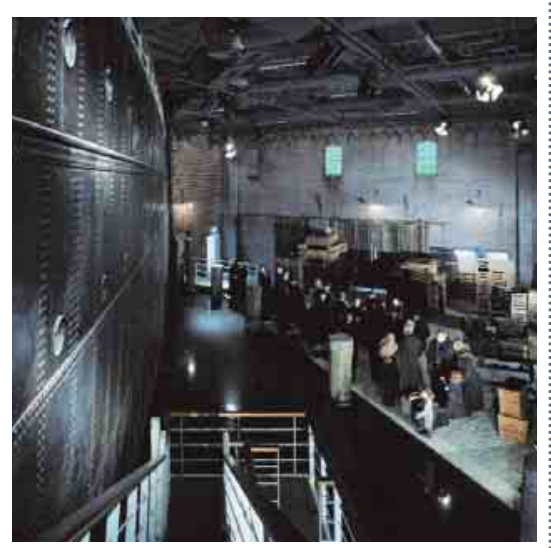

(1) En el embarcadero. Cerman Emigration Center / WERNER HUTHMACHER

The German Emigration Center de Bremerhaven (Alemania) ha sido elegido el Mejor Museo Europeo (EMYA) de 2007, galardón que concede desde hace treinta años el European Museum Forum (EMF). Inaugurado en agosto de 2005, es un museo construido en el lugar del muelle desde donde más de siete millones de emigrantes de Alemania y Europa oriental embarcaron rumbo al continente americano entre 1830 y 1974. El jurado ha valorado las técnicas teatrales e instalaciones multimedia utilizadas para enriquecer la experiencia de los visitantes.

Junto al museo ganador, el European Museum Forum reconoció a otros cuatro centros expositivos: el Museum of the Bresse Region de Saint-Cyr-sur-Methon (Francia), The DolhuysMuseum of Psychia-try de Haarlem (Holanda), The railway Mu-seum de Utrecht (Holanda) y el Paul Klee Centre de Bern (Suiza). Asimismo, el Brunel's ss Great Britain de Bristol (Inglaterra) se llevó el galardón Micheletti que se entrega al museo técnico o industrial más prometedor entre los candidatos.

La designación se ha producido en una gala celebrada en el Museo Arqueológico de Alicante (MARQ), que ganó este premio en 2004, a la que asistieron 150 representantes de museos de 28 países europeos. Allí mismo se anunció que la ciudad de Dublín (Irlanda) acogerá en 2008 la ceremonia de entrega del EMYA, al que ya se han presentado 61 candidaturas de 25 países. 